Article

\title{
Experimental Comparison of Preferential vs. Common Delta Connections for the Star-Delta Starting of Induction Motors
}

\author{
José Augusto Itajiba ${ }^{1, *}$, Cézar Armando Cunha Varnier ${ }^{2}$, Sergio Henrique Lopes Cabral ${ }^{1}$, \\ Stéfano Frizzo Stefenon ${ }^{3,4}$, Valderi Reis Quietinho Leithardt ${ }^{5}\left(\mathbb{D}\right.$, Raúl García Ovejero ${ }^{6}$, Ademir Nied ${ }^{3}$ (D) \\ and Kin-Choong Yow ${ }^{4}$
}

check for updates

Citation: Itajiba, J.A.; Varnier, C.A.C.; Cabral, S.H.L.; Stefenon, S.F.;

Leithardt, V.R.Q.; Ovejero, R.G.; Nied,

A.; Yow, K.-C. Experimental

Comparison of Preferential vs.

Common Delta Connections for the Star-Delta Starting of Induction Motors. Energies 2021, 14, 1318 https://doi.org/10.3390/en14051318

Academic Editor: Anouar Belahcen and Tian-Hua Liu

Received: 25 January 2021

Accepted: 23 February 2021

Published: 1 March 2021

Publisher's Note: MDPI stays neutral with regard to jurisdictional claims in published maps and institutional affiliations.

Copyright: (c) 2021 by the authors. Licensee MDPI, Basel, Switzerland. This article is an open access article distributed under the terms and conditions of the Creative Commons Attribution (CC BY) license (https:/ / creativecommons.org/licenses/by/ $4.0 /)$.
1 Electrical Engineering Graduate Program, Electrical Engineering Department, Regional University of Blumenau, R. São Paulo 3250 (Itoupava Seca), Blumenau 89030-000, Brazil; scabral@furb.br

2 WEG Industries, R. Venâncio da Silva Pôrto 399 (Nova Brasília), Jaraguá do Sul 89252-230, Brazil; cezarv@weg.net

3 Electrical Engineering Graduate Program, Electrical Engineering Department, Santa Catarina State University (UDESC), R. Paulo Malschitzki 200 (North Industrial Zone), Joinville 89219-710, Brazil; stefano.stefenon@udesc.br (S.F.S.); ademir.nied@udesc.br (A.N.)

4 Software Systems Engineering Department, Faculty of Engineering and Applied Science, University of Regina, 3737 Wascana Parkway, Regina, SK S4S 0A2, Canada; kin-choong.yow@uregina.ca

5 VALORIZA, Research Center for Endogenous Resources Valorization, Instituto Politécnico de Portalegre, 7300-555 Portalegre, Portugal; valderi@ipportalegre.pt

6 Expert Systems and Applications Lab., E.T.S.I.I of Béjar, University of Salamanca, 37008 Salamanca, Spain; raulovej@usal.es

* Correspondence: joseitagiba@gmail.com

Abstract: Although this is a fact that is not very explored in the literature, there are two possible forms to connect the stator winding of an induction motor in the delta. The choice for one of these forms defines the amplitude of the stator transient current during the switching from star to delta connection when the motor is driven by a star-delta starting system, which is the most widely used and diffused method for starting an induction motor. One of the possible forms of the delta connection gives rise to a switching current with a relatively small amplitude, which gives it the denomination of preferential. The other form has a relatively higher amplitude of switching current, but it is the most recommended and indicated in diagrams of catalogues and motor plates. Therefore, it is here called "common". With the aim of evidencing how the differences between these two forms of delta connection are manifested, this paper approaches the issue experimentally, through a methodology with statistical support, for a better characterization of the performance of each of these forms of delta connection, in the case of the widely popular star-delta starting method.

Keywords: induction motor; delta connections; star-delta starting

\section{Introduction}

Despite the growing availability and the consequent increase in the use of electronic devices for the soft starting of the induction motor, such as the soft starter and the VFD -Variable frequency drive - the traditional star-delta starting method, mainly composed of contactors and timing relays, remains one of the most usual and preferred options for most drive systems in the industry [1]. This is especially true in the case of relatively small automation systems, be it new or an already running one [2], due to its relatively low cost as well as the wide availability of services for its installation and maintenance, besides its robustness as a whole [3].

Currently, many electrical drives perform with equipment that has switched converters; these have a flexible application and become economically advantageous as the power of the motors has increased. However, this type of starter has disadvantages such as noise from its switching and high cost for low power motors. The use of static converters is 
gaining more and more space as they are robust equipment and have become economically viable with developments in semiconductor materials; this expansion means that fewer and fewer starts are used that need to change the way the motor is connected, such as the star-delta starting, compensating start and parallel start [4]. The definition of a preferred way to start engines is rarely addressed in the literature, considering that there may be variations when engines of different powers are evaluated.

The preferred start is rarely addressed in the literature, although some works address the variations of possible delta connections and their consequences in the electrical system [4]. Some surveys are focused on starting with drives [5] and in a large part of the research the improvement of the engine efficiency is evaluated through the use of more modern materials [6] and optimization of machine parameters [7-9].

In fact, the star-delta starting is one of the most classic methods of starting an induction motor [10]. As with many other starting methods, it is based on the reduction in the voltage amplitude applied to the stator winding at the start, to decrease the stator current [11]. In this case, the value of the amplitude of the applied voltage is $1 / \sqrt{3}$ of the rated voltage at the start, because of the star connection of the stator winding, which causes an equal reduction in the value of the amplitude of the stator current [12]. Thus, a while after the start of the motor, which is adjusted by the operator, the connection of the stator winding is automatically switched to the delta, and so it remains in the steady-state [13].

For this purpose, there is a wide variety of models and manufacturers on the market for the star-delta switch, which can bring together several devices to perform this type of start in a single device. In addition to contactors, these switches should have overcurrent relays, fuses, and timing relays, which allow the operator to adjust the time interval during which the motor will run as star-connected. After this interval has elapsed, the star connection of the stator winding is undone, and the motor runs idle for a short period, usually $\Delta \mathrm{t}=100 \mathrm{~ms}$, adopted by most manufacturers of these switches, before the delta connection of the stator winding is performed. Then, at the instant that this connection is made, there is a sudden increase in the amplitude of the stator current, which must be accepted by the motor protection system, so as not to unduly take it as a fault current [3].

Figure 1 shows a graphic with the expected performance of the stator current of the motor along this process, with an indication of the sudden increase in the current. Figure 1 is a representation of the variation that occurs in the transient. Right after receiving the command to break the circuit, the contactor opens its contacts by generating an arc per each phase that is properly quenched within a chamber until it passes to zero. Therefore, the three-phase current continues to flow for some milliseconds, approximately.

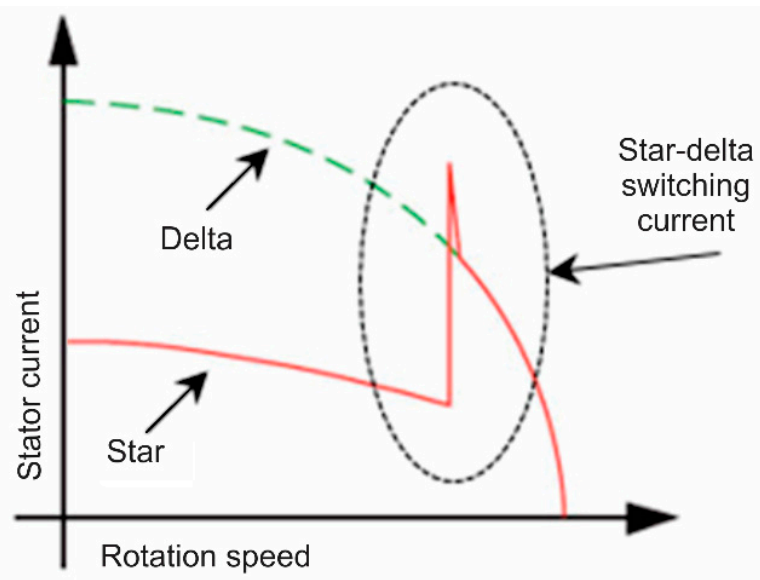

Figure 1. Stator current behavior in star-delta start-switching overcurrent.

Although the graphic of Figure 1 shows that the sudden increase in the stator current may be a natural consequence of switching from the star to the delta connection, the real reasons for this sudden increase are not so obvious. In fact, the amplitude of such 
an overcurrent is strongly influenced by the form of connection adopted for the delta connection of the stator winding [14].

According to [15] and [16] in the choice between delta connection forms, one of them will present a relatively smaller amplitude of switching current and is therefore considered as a delta connection in the preferential form. Consequently, the other form presents an amplitude of switching current with higher values but, curiously, it is the most commonly found form in motor plates and/or recommended by installation diagrams.

Therefore, it is called the common form. The difference between both forms of delta connection is only in the inversion of the connection of the terminals of one of the stator windings, without which there may be a reversal of the rotation direction of the motor shaft since the phase sequence of the power supply is not inverted [17]. Thus, with a few exceptions in the literature, as in [18] and [19], the importance of the correct choice between these two forms of connecting the stator winding in the delta is not properly diffused or explored, and so this is the essence of this work. The diagrams in Figure 2 show the two possible forms of delta connection.
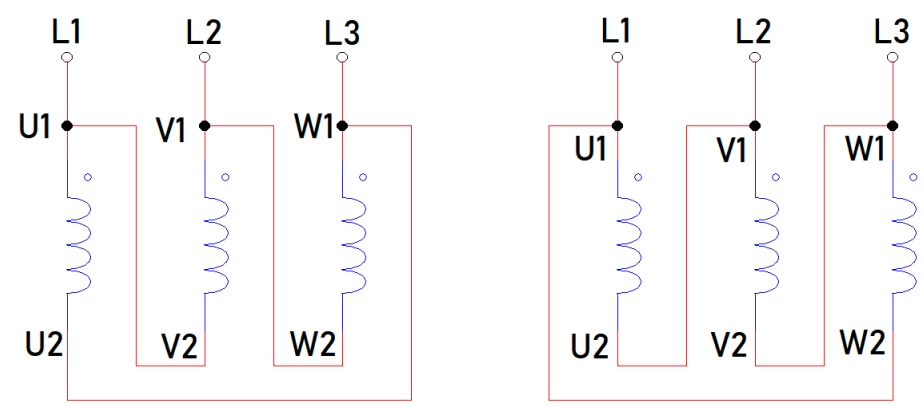

Figure 2. The two possibilities of connection in delta. Preferential on the left and common on the right.

According to [18], this difference in the amplitude of the switching current occurs because, invariably, there is a residual magnetic field, both in the rotor magnetic circuit and in the stator magnetic circuit. Therefore, the rotor movement causes both residual fields to mutually induce a voltage in the respective circuits during the short time interval in which the motor runs idle, $\Delta \mathrm{t}$. Thus, depending on whether the delta connection is made in the preferential form or in the common one, the combination of the mutually induced voltage will give different results, causing the amplitude of the switching current to have significantly different values at the right instant of the delta connection.

As can be seen in Figure 2, there are two ways to connect a star-delta starter in an induction motor; however, this difference is little discussed considering that the industry determines a preferred way to start the induction motor. In this way, this paper addresses an important subject for the study of induction motors, evaluating the differences in the alteration of the preferred form of connection for induction motors.

In [18] there is a proposing explanation for this fact, with the help of phasor diagrams, which does not consider any residual magnetic field and thus requires some refinement. On the other hand, it is important to consider that the influence of the form of the delta connection superimposes on the effect of the inertia of the rotor, which naturally causes the reduction in its speed. This reduction in the speed is due to the time elapsed $(\Delta t)$ since the star connection of the stator winding is undone until the instant they are connected in delta [20].

Therefore, since the motor runs idle along with this time interval, an additional amount of stator current will be necessary to accelerate the rotor and compensate for the loss of its kinetic energy [21], which represents a part of the total switching current. Thus, since this part of the switching current does not depend on the form of delta connection, for the same load condition of a given motor, the reason for the common connection to give a total switching current with a higher amplitude relies on the residual magnetic field of 
the magnetic circuit of the motor. Specific projects are needed to improve the efficiency of electrical machines [22-24], and thus meet the development of the industrial sector in a sustainable manner [25].

To improve energy quality and increase machine efficiency, specific projects have been developed [26], as highlighted by Orosz et al. [27], who present a study highlighting open problems related to electric machines and highlighting how optimization can help in the development of emerging technologies. Optimization is undergoing this great evolution due to the higher analysis capabilities and can be used in various applications, such as electrical transformers [28] and autotransformers [29], among other applications [30]. Research that applies artificial intelligence and modern methods of evaluation of the consequences of parameter changes is promising for addressing the optimization problems [31,32].

However, since there is an influence of the residual value of the magnetic field that varies sinusoidally over time, this value itself is not constant but depends on several factors that are difficult to evaluate or to assess, especially the instantaneous values of the current and voltage on the stator before and after the switching, as well as the motor temperature, among others [33]. Thus, the occurrence of a greater amplitude of the switching current for the common form of star connection is of a statistical nature. Consequently, several starts of the same motor are required, with each of the forms of delta connections to evaluate the behavior of the switching current.

It is important to mention that the peak current does not depend on the residual magnetic field and the residual voltage induced by this field in the stator winding only, but also significantly on the phase difference between the residual voltage and the supply voltage in the instant of the reconnection of the motor to the supply in the delta connection [34]. This phase difference, as well as the residual voltage, is not only influenced by the switching time $\Delta t$ and the alternative chosen for delta connection, but also by parameters like inertia, load torque, and stator leakage [35].

For this purpose, an experimental arrangement was elaborated to, firstly, check the occurrence of differences in the amplitude of the switching current according to the form of the delta connection, and then to characterize this difference in amplitude.

\section{Materials and Methods}

In view of the analysis of the differences in amplitude of the switching current for the common and the preferential forms of delta connection, a prototype of a drive system was assembled in the laboratory to enable the sequential use of each of the two forms of delta connection, with the start of the motor in star connection of the stator winding. As a sample, a standard three-phase induction motor was used. It was a $380-\mathrm{Y} / 220-\Delta \mathrm{V}, 4$ poles, $0.75 \mathrm{~kW}, 1730 \mathrm{rpm}$, squirrel cage, $\mathrm{SF}=1.15$ and continuous duty $\mathrm{S} 1$ type of motor. The power circuit of the drive system, with an indication of some contactors providentially taken for the proposed type of drive, is shown in the diagram in Figure 3.

The channels shown in Figure 3 represent the connection of the experiment for measuring voltage and current that was used in the laboratory analysis. As shown in the diagram, four contactors are used. Initially, the contactor K1 energizes the terminals 1, 2, and 3 of the stator winding. Then, the contactor K4 short-circuits the other terminals, 4, 5, and 6, making the connection in star. After the time interval $(\Delta t)$ is previously set to the timing relay, the star connection is undone through the opening of the contactor $\mathrm{K} 4$, and the stator windings are then connected in delta. By doing so, the contactor K2 allows the delta connection in the common form, whereas the contactor $\mathrm{K} 3$ allows the preferential form.

Regarding the control circuit, although there are many commercial models of star-delta starting solutions, fitted with timers or not, Misir et al. [36] developed a specific solution, since most of them do not allow the choice between the common or the preferential form. Moreover, commercial switches do not allow adjustment of the time interval between the star and the delta connections $(\Delta t)$ which hinders the analysis of the influence of the inertia of the motor rotor on the amplitude of the switching current to the delta connection. For example, this time interval could then be set to $50 \mathrm{~ms}$, besides the usual $100 \mathrm{~ms}$. To do so, a 
PLC-Programmable Logic Controller was chosen for use in the control circuit, allowing significant simplicity in implementation of the desired actions and easy communication through a serial interface.

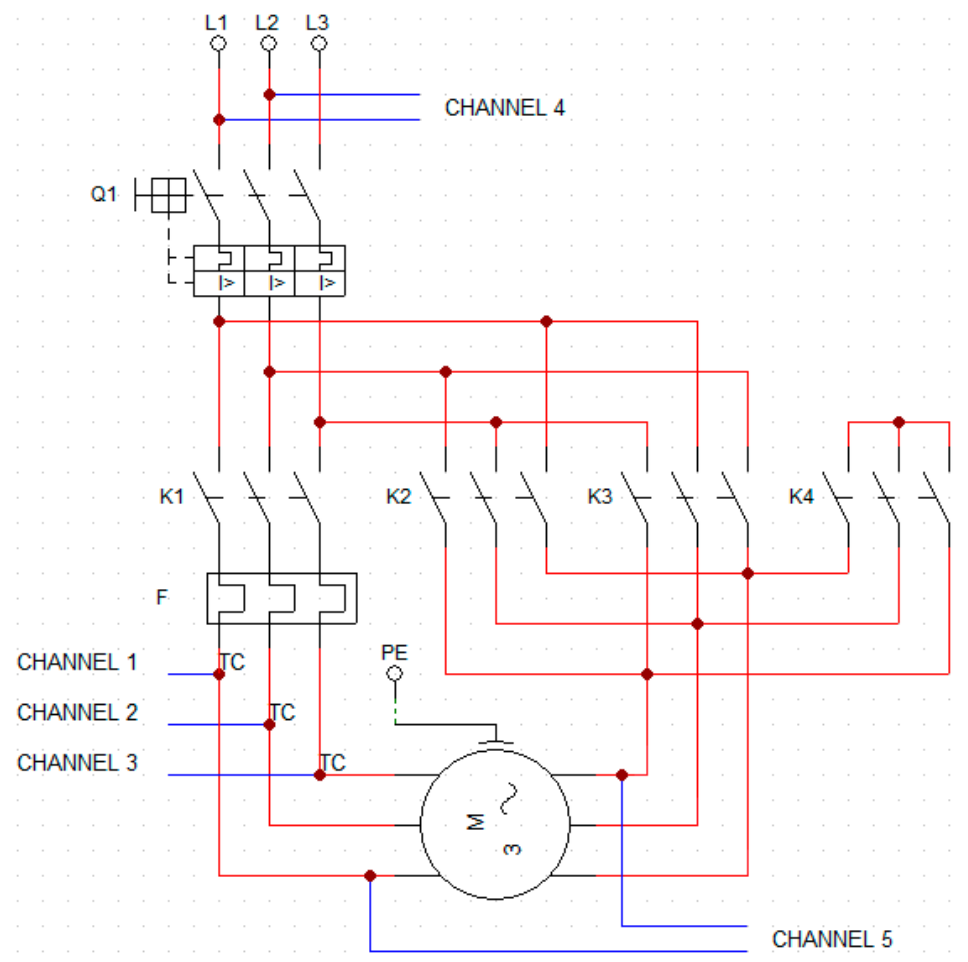

Figure 3. Diagram of the power circuit (main) of the proposed drive system.

The PLC model adopted was Siemens ${ }^{\circledR}$ S7-200, Blumenau, Brazil, and Figure 4 shows a photo of the complete arrangement, containing the command and power circuits, assembled on a laboratory bench, proper for induction motor tests. In the foreground are the contactors and the fuses in one of the boards, whereas on the right is the adopted PLC. Between the motor, taken at the idle mode, and the contactors/fuses board there is an autotransformer to adjust the available mains voltage from $380 \mathrm{~V}$ to $220 \mathrm{~V}$ as required by the windings of the motor stator.

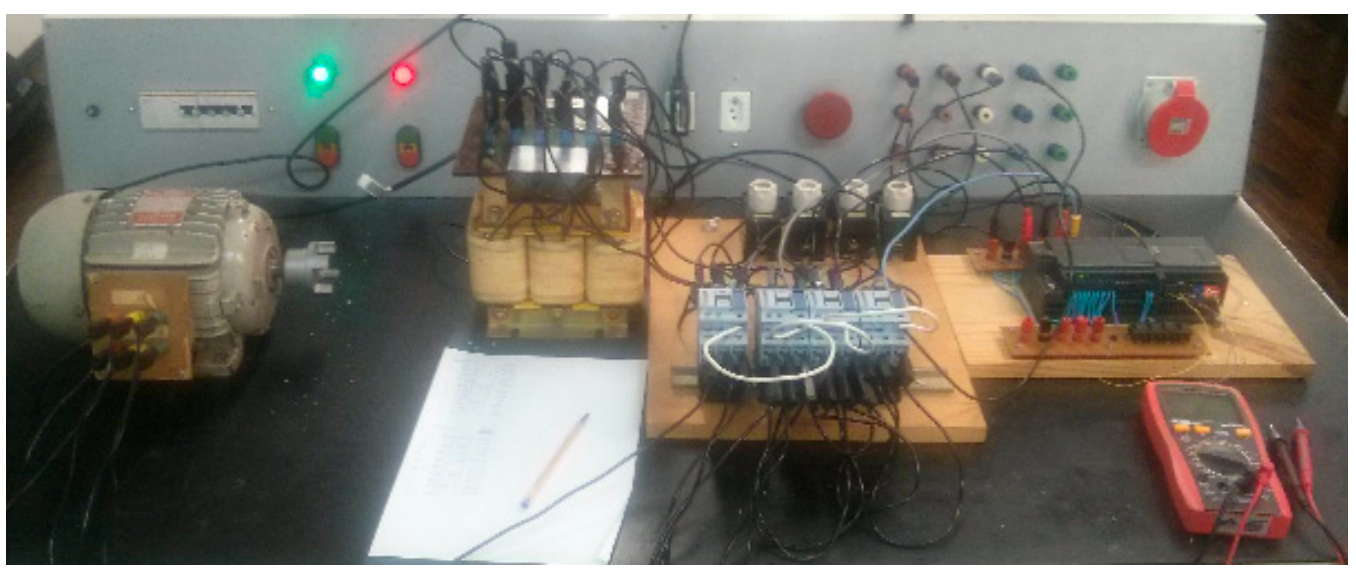

Figure 4. Arrangement of star-delta starting tests for analysis.

A star-delta starter is a low voltage starter used to reduce the starting current of the motor. The great advantage of the star-delta starter is its need to use $1 / 3$ of the peak current 
compared to a direct starting. For this consideration, having $V_{L}=$ supply line voltage, $I_{L S}=$ supply line current and, $I_{P S}=$ winding current per phase and $Z=$ impedance per phase winding at stand still condition.

When the winding is star connected, the $I_{P S}$ is equal to the $I_{L S}$. Then, the voltage in each phase of the winding is $V_{L} / \sqrt{3}$. Since here, the $I_{P S}$ equals to the $I_{L S}$, it can be written

$$
I_{P S}=\frac{V_{L}}{\sqrt{3} Z} \leftrightarrow I_{L S}=\frac{V_{L}}{\sqrt{3} Z} .
$$

When the winding is delta connected, the $\left(I_{L D}\right)$ supply line current is root three times of the winding $\left(I_{P D}\right)$ current per phase, the voltage in each phase of the winding is $V_{L}$. Thus, the winding current per phase is $V_{L} / Z$. Rewriting the equation

$$
I_{L D}=\sqrt{3} I_{P D}=\frac{\sqrt{3} V_{L}}{Z} .
$$

In this way comparing the equations

$$
\frac{I_{L D}}{I_{L S}}=\frac{\frac{\sqrt{3} V_{L}}{Z}}{\frac{V_{L}}{\sqrt{3} Z}}=3 .
$$

In this way, it is possible to say that the starting current of the network in the case of delta star is one third of the direct switching in the delta.

The voltage equation for a motor consists of the evaluation of the following components: the voltage drop of the winding resistance $R$, the induced voltage proportional to the rate of change over time of the winding flow connection $\lambda$, as follows:

$$
v(t)=R i(t)+\frac{d \lambda(t)}{d t}=R i(t)+\frac{d\left[L\left(\theta_{r}\right) i(t)\right]}{d t},
$$

wherein $\theta_{r}=\omega_{r} t$.

Considering a three-phase and bipolar induction motor, whereas the stator windings have a number of effective turns $N_{s}$, resistance $R_{S}$, leakage inductance $L_{1 s}$ and selfinductance $L_{s}$. Likewise, the equivalent rotor windings have a number of effective turns $\mathrm{Nr}$, resistance $\mathrm{Rr}$, leakage inductance $L_{1 r}$ and self-inductance. $\theta_{r}$ is the angular displacement between the stator and rotor axes, disregarding nonideal features such as groove effect, saturation of the iron core and toothed torque [37].

The winding voltage is given by the sum of the voltage drop of the winding resistance and the voltage induced by the variation of the winding flow connection. Thus, by deriving the voltage range of an induction motor, the six voltage equations for the stator and rotor windings can be calculated by

$$
\begin{aligned}
& v_{a s}=R_{s} i_{a s}+\frac{d \lambda_{a s}}{d t} \\
& v_{b s}=R_{s} i_{b s}+\frac{d \lambda_{b s}}{d t}
\end{aligned}
$$

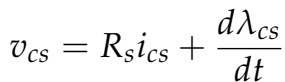

$$
\begin{aligned}
& v_{a r}^{\prime}=R^{\prime} i_{a r}^{\prime}+\frac{d \lambda_{a r}^{\prime}}{d t} \\
& v^{\prime}{ }_{b r}=R^{\prime} i^{\prime}{ }_{b r}+\frac{d \lambda^{\prime}{ }_{b r}}{d t} \\
& v^{\prime}{ }_{c r}=R^{i^{\prime}{ }^{\prime} c r}+\frac{d \lambda_{c r}^{\prime}}{d t}
\end{aligned}
$$


wherein $v_{a s}, v_{b s}, v_{c s}$ are the stator voltages, $i_{a s}, i_{b s}, i_{v s}$ are the stator currents, $v^{\prime}{ }_{a r}, v^{\prime}{ }_{b r}, v^{\prime}{ }_{c r}$ are the rotor voltages, $i_{a r}^{\prime}, i_{c r}^{\prime}$ are the rotor currents, $\lambda_{a s}, \lambda_{b s}, \lambda_{c s}$ are the stator flux linkages, $\lambda_{a r}, \lambda_{b r}, \lambda_{c r}$ are the rotor flux linkages.

To solve these voltage equations, it is necessary to know the flow connection of each winding. Considering that there are six windings, each of them will be influenced by the flow produced by the current flowing in the other five windings. Therefore, the full flow connection $\lambda$ from the phase as the winding has the following six components:

$$
\lambda_{a s}=\lambda_{a s a s}+\lambda_{a s b s}+\lambda_{a s c s}+\lambda_{a s a r}+\lambda_{a s b r}+\lambda_{a s c r}
$$

Therefore,

$$
\lambda_{a s}=L_{a s a s} i_{a s}+L_{a s b s} i_{b s}+L_{a s c s} i_{c s}+L_{a s a r} i_{a r}+L_{a s b r} i_{b r}+L_{a s c r} i_{c r}
$$

where the flow connection $\lambda_{x s y s}$ represents the flow, which is produced by the current $i_{y s}$ flowing in winding $y s$ and connecting winding $x s$. The inductance $L_{x s y s}$ is determined as the ratio of the flux that connects the winding $x s$ to the current $i_{y s}$ that generates the flux. Thus, the six flux linkages in the stator and rotor windings can be calculated by:

$$
\left[\begin{array}{l}
\lambda_{a s} \\
\lambda_{b s} \\
\lambda_{c s} \\
\lambda_{a r} \\
\lambda_{b r} \\
\lambda_{c r}
\end{array}\right]=\left[\begin{array}{llllll}
\lambda_{a s a s} & \lambda_{a s b s} & \lambda_{a s c s} & \lambda_{\text {asar }} & \lambda_{\text {asbr }} & \lambda_{\text {ascr }} \\
\lambda_{b s a s} & \lambda_{b s b s} & \lambda_{b s c s} & \lambda_{b s a r} & \lambda_{b s b r} & \lambda_{b s c r} \\
\lambda_{c s a s} & \lambda_{c s b s} & \lambda_{c s c s} & \lambda_{c s a r} & \lambda_{c s b r} & \lambda_{c s c r} \\
\lambda_{a r a s} & \lambda_{a r b s} & \lambda_{a r c s} & \lambda_{a r a r} & \lambda_{a r b r} & \lambda_{a r c r} \\
\lambda_{b r a s} & \lambda_{b r b s} & \lambda_{b r c s} & \lambda_{b r a r} & \lambda_{b r b r} & \lambda_{b r c r} \\
\lambda_{c r a s} & \lambda_{c r b s} & \lambda_{c r c s} & \lambda_{c r a r} & \lambda_{c r b r} & \lambda_{c r c r}
\end{array}\right]
$$

wherein,

$$
\left[\begin{array}{l}
\lambda_{a s} \\
\lambda_{b s} \\
\lambda_{c s} \\
\lambda_{a r} \\
\lambda_{b r} \\
\lambda_{c r}
\end{array}\right]=\left[\begin{array}{llllll}
L_{a s a s} & L_{a s b s} & L_{a s c s} & L_{a s a r} & L_{a s b r} & L_{a s c r} \\
L_{b s a s} & L_{b s b s} & L_{b s c s} & L_{b s a r} & L_{b s b r} & L_{b s c r} \\
L_{c s a s} & L_{c s b s} & L_{c s c s} & L_{c s a r} & L_{c s b r} & L_{c s c r} \\
L_{a r a s} & L_{a r b s} & L_{a r c s} & L_{a r a r} & L_{a r b r} & L_{a r c r} \\
L_{b r a s} & L_{b r b s} & L_{b r c s} & L_{b r a r} & L_{b r b r} & L_{b r c r} \\
L_{c r a s} & L_{c r b s} & L_{c r c s} & L_{c r a r} & L_{c r b r} & L_{c r c r}
\end{array}\right]\left[\begin{array}{l}
i_{a s} \\
i_{b s} \\
i_{c s} \\
i_{a r} \\
i_{b r} \\
i_{c r}
\end{array}\right] .
$$

Writing in compact form the inductances can be divided into four groups, according to:

$$
\left[\begin{array}{l}
\lambda_{a b c s} \\
\lambda_{a b c r}
\end{array}\right]=\left[\begin{array}{cc}
\boldsymbol{L}_{s} & \boldsymbol{L}_{s r} \\
{\left[\boldsymbol{L}_{s r}\right]^{T}} & \boldsymbol{L}_{r}
\end{array}\right]\left[\begin{array}{l}
\boldsymbol{i}_{a b c s} \\
\boldsymbol{i}_{a b c r}
\end{array}\right]
$$

thereby, $L_{s}$ is the inductance matrix of the stator windings, $L_{r}$ is the inductance matrix of the rotor windings, and $L_{s r}$ is the mutual-inductance matrix between the stator and rotor windings.

The $\boldsymbol{L}_{S}$ stator inductance matrix consists of the mutual inductance between the stator windings and the self-inductances of each stator winding. The stator self-inductances consist of the sum of the leakage $L_{l s}$ inductance and $L_{m s}$ magnetizing inductance, according to

$$
L_{a s a s}=L_{b s b s}=L_{c s c s}=L_{l s}+L_{m s}
$$

where,

$$
L_{m s}=\mu_{0} N_{s}^{2}\left(\frac{r l}{g}\right)\left(\frac{\pi}{4}\right)
$$

wherein, $\mu_{0}$ is the permeability of air, $r$ is the radius of the air gap, and $l$ is the axial length of the air gap. 
The mutual inductances between the two stator windings are all equal and related to the inductance of magnetization as:

$$
L_{a s b s}=L_{a s c s}=L_{b s a s}=L_{b s c s}=L_{c s a s}=L_{c s b s}=L_{m s} \cos \left(\frac{2 \pi}{3}\right)=-\frac{1}{2} L_{m s} .
$$

The inductances of the stator windings are given by

$$
\boldsymbol{L}_{s}=\left[\begin{array}{ccc}
L_{a s a s} & L_{a s b s} & L_{a s c s} \\
L_{b s a s} & L_{b s b s} & L_{b s c s} \\
L_{c s a s} & L_{c s b s} & L_{c s c s}
\end{array}\right]=\left[\begin{array}{ccc}
L_{l s}+L_{m s} & -\frac{L_{m s}}{2} & -\frac{L_{m s}}{2} \\
-\frac{L_{m s}}{2} & L_{l s}+L_{m s} & -\frac{L_{m s}}{2} \\
-\frac{L_{m s}}{2} & -\frac{L_{m s}}{2} & L_{l s}+L_{m s}
\end{array}\right] .
$$

For the inductance of the rotor windings $L_{r}$, the rotor self-inductance $L_{a r a r}, L_{b r b r}, L_{c r c r}$ consist of the leakage inductance $L_{l r}$ and the magnetizing inductance $L_{m r}$, so it has:

$$
L_{a r a r}=L_{b r b r}=L_{c r c r}=L_{l r}+L_{m r}
$$

where,

$$
L_{m r}=\mu_{0} N_{r}^{2}\left(\frac{r l}{g}\right)\left(\frac{\pi}{4}\right)=\left(\frac{N_{r}}{N_{s}}\right)^{2} L_{m s}
$$

The mutual inductances between the two rotor windings are all equal and related to the inductance of magnetization as:

$$
L_{a r b r}=L_{a r c r}=L_{b r a r}=L_{b r c r}=L_{c r a r}=L_{c r b r}=L_{m r} \cos \left(\frac{2 \pi}{3}\right)=-\frac{1}{2} L_{m r}=-\frac{1}{2}\left(\frac{N_{r}}{N_{s}}\right)^{2} L_{m s}
$$

where $N r / N s$ is the turns ratio of the stator and rotor windings $n$, inductances of the rotor windings are given by

$$
\boldsymbol{L}_{r}=\left[\begin{array}{ccc}
L_{a r a r} & L_{a r b r} & L_{a r c r} \\
L_{b r a r} & L_{b r b r} & L_{b r c r} \\
L_{c r a r} & L_{c r b r} & L_{c r c r}
\end{array}\right]=\left[\begin{array}{ccc}
L_{l s}+n^{2} L_{m s} & -n^{2} \frac{L_{m s}}{2} & -n^{2} \frac{L_{m s}}{2} \\
-\frac{L_{m s}}{2} & L_{l s}+n^{2} L_{m s} & -n^{2} \frac{L_{m s}}{2} \\
-n^{2} \frac{L_{m s}}{2} & -n^{2} \frac{L_{m s}}{2} & L_{l s}+n^{2} L_{m s}
\end{array}\right]
$$

The same analysis is performed to inductance between the stator and rotor windings $L_{s r}$, considering the rotating at a speed $w_{r}$, the relative position $\theta_{r}$, which is the displacement angle [37]. Considering the turns ratio between the two windings, we have:

$$
L_{a s a r}=L_{m r}\left(\frac{N_{s}}{N_{r}}\right) \cos \left(\theta_{r}\right)=\left(\frac{N_{r}}{N_{s}}\right) L_{m s} \cos \left(\theta_{r}\right), \quad\left(\theta_{r}=\int \omega_{r} d t\right) .
$$

So we have the other mutual-inductances

$$
\begin{gathered}
L_{a s a r}=L_{b s b r}=L_{c s c r}=\left(\frac{N_{r}}{N_{s}}\right) L_{m s} \cos \left(\theta_{r}\right) \\
L_{a s b r}=L_{b s c r}=L_{c s a r}=\left(\frac{N_{r}}{N_{s}}\right) L_{m s} \cos \left(\theta_{r}+\frac{2 \pi}{3}\right) \\
L_{a s c r}=L_{b s a r}=L_{c s b r}=\left(\frac{N_{r}}{N_{s}}\right) L_{m s} \cos \left(\theta_{r}-\frac{2 \pi}{3}\right) .
\end{gathered}
$$

So the matrix $L_{s r}$ is given by:

$$
\boldsymbol{L}_{s r}=\left[\begin{array}{lll}
L_{a s a r} & L_{a s b r} & L_{a s c r} \\
L_{b s a r} & L_{b s b r} & L_{b s c r} \\
L_{c s a r} & L_{c s b r} & L_{c s c r}
\end{array}\right]=n L_{m s}\left[\begin{array}{ccc}
\cos \left(\theta_{r}\right) & \cos \left(\theta_{r}+\frac{2 \pi}{3}\right) & \cos \left(\theta_{r}-\frac{2 \pi}{3}\right) \\
\cos \left(\theta_{r}-\frac{2 \pi}{3}\right) & \cos \left(\theta_{r}\right) & \cos \left(\theta_{r}+\frac{2 \pi}{3}\right) \\
\cos \left(\theta_{r}+\frac{2 \pi}{3}\right) & \cos \left(\theta_{r}-\frac{2 \pi}{3}\right) & \cos \left(\theta_{r}\right)
\end{array}\right]
$$


Finally, from Equations (19), (23), and (28) for the calculation inductance of the stator and rotor windings, and mutual-inductance the full flow connections of the induction motor are obtained.

As an analytical approach for trying to elucidate this problem, the authors consider the hysteresis model suggested by [38] that was applied to transformers. In this case, minor but providential adaptations were added to that model by including the leakage inductance, for its inherent and significant influence, as well as by considering the value of the circuit parameters of the stator and the rotor as being the equivalent and referred to the primary, that is the stator.

The basic principle of hysteresis can be described through two principles; the first is related to the magnetization curve, with the presence of saturation, which is mathematically fitted with any function that adds signal coherence. In the second, the magnetization current will always present the static and dynamic components, described by:

$$
i(\lambda, t)=i(\lambda(t))+k \frac{d \lambda(t)}{d t}
$$

where $\lambda(t)$ is the magnetic flux linkage along the time and $\mathrm{k}$ is a constant of proportionality.

Considering that the Equation (29) must be derived for Ohm's and applying Lenz's law to the winding circuit we obtain:

$$
V(t)=r i(t)+k \frac{d \lambda(t)}{d t}
$$

Based on this, it seems to be clear how effective the influence of the residual magnetism is on the instantaneous value of the current by including the fact that it contributes for not allowing us to affirm that the initial value of this current should be null. Moreover, it shows how the instantaneous voltage has similar influence on the instantaneous values of the current. Nonetheless, the influence of the choice for the preferential or common connection does not seem clear, since any choice does not represent a change in the phasor voltage sequence that would cause the rotor to invert its rotating direction.

At last, due to its key influence, the observed difference in the behavior of the residual magnetism for the common and preferential connections seems to be the most important item to be researched. For its turn, its initial value and behavior also have not electrical or magnetic influences but mechanical, as the percent of the rated load, instantaneous speed and even thermal conditions of the magnetic circuit of the inductions motor. This challenging scenario has made the authors investigate this problem experimentally in view of contributing to addressing this very unclear issue.

In the analysis, the current of 10 starts are evaluated, for which the average and standard deviation are calculated. The standard deviation is given by:

$$
s t d \_D e v=\frac{1}{n-1} \sum_{p=1}^{n}\left(y_{i, p}-\overline{y_{i}}\right)^{2},
$$

wherein, $y_{i, p}$ is the value of the predicted output $i$ in object $p$ and $\overline{y_{i}}$ is the average of the variable $i$.

\section{Results}

To check under what conditions the difference between the values of the switching current to the delta commutation occurs in the common and preferential forms, ten starts were performed for each of these two forms. In each of the starts, the motor was in the resting state without any load on its shaft and was run for only a few minutes. In order to record the transient current, the current probe Tektronix ${ }^{\circledR}$ model A-622, Blumenau, Brazil, was connected to an oscilloscope and applied to the same phase.

First, the model was applied to the common form of delta connection, to serve as a reference. Ten starts were performed and the waveform of the switching current of the delta 
connection was recorded (see Table 1). The presented results show that, except for two of the occurrences, with 9.4 and $11 \mathrm{~A}$, the amplitude of the switching current is characterized by an average and homogeneous value of about $18 \mathrm{~A}$. However, the most important result is that the value of the amplitude of the switching current is not repetitive, which confirms the statistical nature of the event and the influence of the residual magnetism, as previously mentioned.

Table 1. Amplitude of switching current $-\Delta \mathrm{t}=100 \mathrm{~ms}$.

\begin{tabular}{ccc}
\hline Start & $\begin{array}{c}\text { Amplitude (A) for the } \\
\text { Common Form }\end{array}$ & $\begin{array}{c}\text { Amplitude (A) for the } \\
\text { Preferential Form }\end{array}$ \\
\hline 1 & 18.2 & 13.0 \\
2 & 11.4 & 10.2 \\
3 & 17.8 & 12.2 \\
4 & 18.0 & 13.0 \\
5 & 18.0 & 7.8 \\
6 & 18.0 & 9.2 \\
7 & 17.8 & 13.0 \\
8 & 18.2 & 9.8 \\
9 & 9.4 & 14.4 \\
10 & 11.0 & 13.6 \\
Average & 15.8 & 11.6 \\
Std Deviation & 3.4 & 2.1 \\
\hline
\end{tabular}

For the sake of illustration, Figure 5 shows a typical waveform of the switching current of the delta connection for the ten different starts performed.

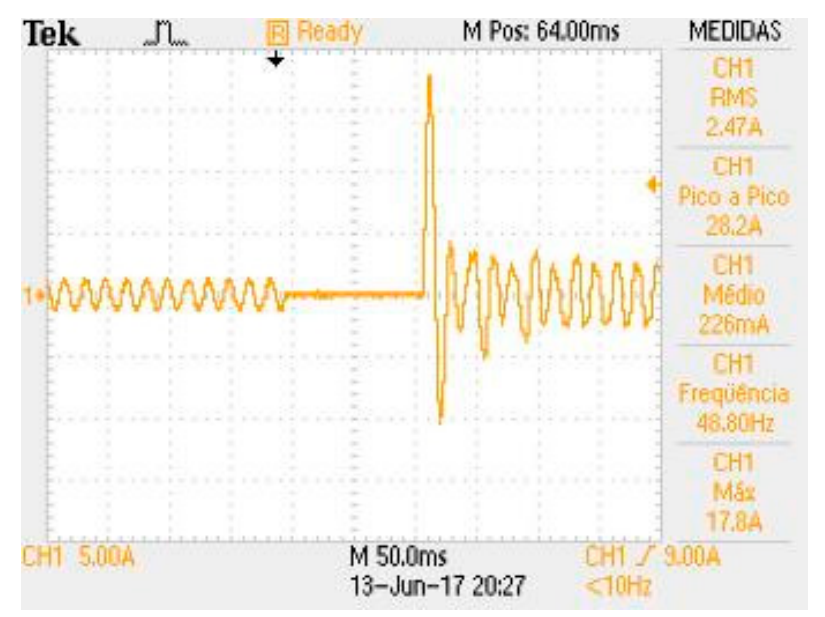

Figure 5. Typical current waveform for the common form of delta connection $-\Delta t=100 \mathrm{~ms}$. (Vertical scale -5 A/division; Horizontal scale -50 ms per division).

In the sequence, ten starts were performed for the same motor, under the same conditions, except for the delta connection in the preferential form. Table 1 shows the experimentally obtained values for the amplitude of the switching current for each of the ten starts, with the time interval between the star and delta connections $(\Delta t)$ set to $100 \mathrm{~ms}$.

As expected, for the preferential form of the delta connection, the average value for the amplitude of the switching current is significantly lower than that obtained for the common form, which justifies it being given the designation. In addition, it can be noticed that the variation of values around the average value, or the mean deviation, is also smaller than in the common form.

Thus, for the sake of illustration, Figure 6 shows a typical waveform of the switching current for the preferential form of delta connection, with the same value of $\Delta \mathrm{t}, 100 \mathrm{~ms}$. 


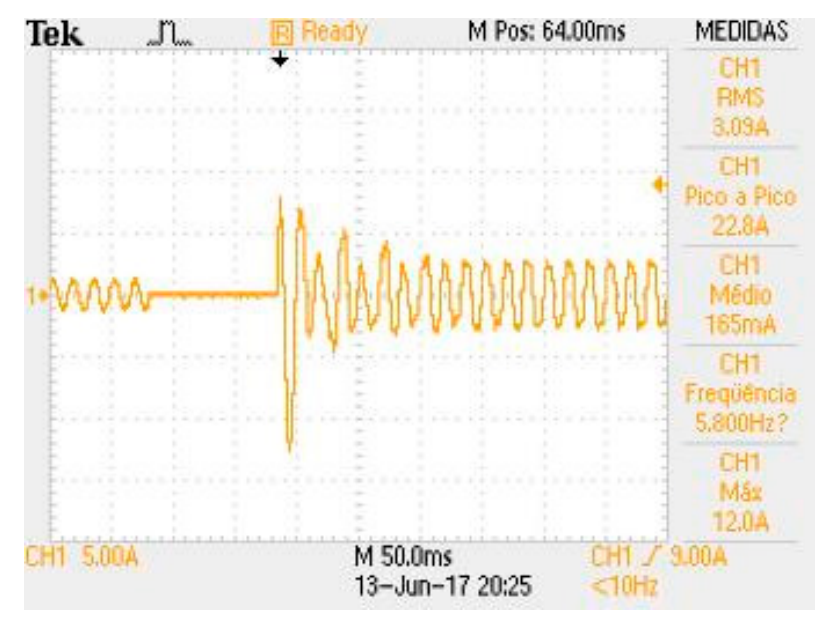

Figure 6. Typical current waveform for the preferential form of delta connection $-\Delta t=100 \mathrm{~ms}$ (Vertical scale-5 A/division; Horizontal scale-50 ms per division).

In this case, the value of the amplitude of the switching current was about $13 \mathrm{~A}$, with negative polarity. In the sequence, ten other starts of the same motor were performed, in the same conditions as before, with the connection in the common and preferential forms, but with a value of $\Delta t$ set to $50 \mathrm{~ms}$.

The expectation for the results of these tests was that the average value of the amplitude would be significantly smaller than that for the similar conditions of before, since a smaller time interval $(\Delta t)$ does not allow a significant loss of the rotor speed due to its inertia, and thus, a smaller amount of power is required from the power grid in the form of part of the switching current to compensate for the unavoidable loss of speed (see Table 2).

Table 2. Amplitude of the switching current $-\Delta t=50 \mathrm{~ms}$.

\begin{tabular}{ccc}
\hline Start & $\begin{array}{c}\text { Amplitude (A) For the } \\
\text { Common Form }\end{array}$ & $\begin{array}{c}\text { Amplitude (A) for the } \\
\text { Preferential Form }\end{array}$ \\
\hline 1 & 10.8 & 9.6 \\
2 & 11.4 & 9.4 \\
3 & 15.2 & 6.2 \\
4 & 11.4 & 11.2 \\
5 & 15.2 & 7.2 \\
6 & 15.2 & 7.0 \\
7 & 15.2 & 12.0 \\
8 & 9.2 & 6.8 \\
9 & 15.6 & 11.0 \\
10 & 11.4 & 11.6 \\
Average & 13.1 & 9.2 \\
Std Deviation & 2.3 & 2.1 \\
\hline
\end{tabular}

From a comparison with the results obtained with those of this same form of delta connection, but with $\Delta \mathrm{t}$ set in $100 \mathrm{~ms}$, shown in Table 1, it is observed that, on average, the amplitude of the switching current becomes significantly smaller, although the value of the mean deviation is the same, which confirms the expectations. On the other hand, it is interesting to note that, on average, the amplitude of the switching current for the common form of delta connection with $\Delta \mathrm{t}=50 \mathrm{~ms}$ is still significantly higher than that for the preferential form with a higher value of $\Delta \mathrm{t}, 100 \mathrm{~ms}$.

A typical waveform of the switching current, in the function of time, is shown in Figure 7 for the common form and $\Delta \mathrm{t}$ set to $50 \mathrm{~ms}$. 


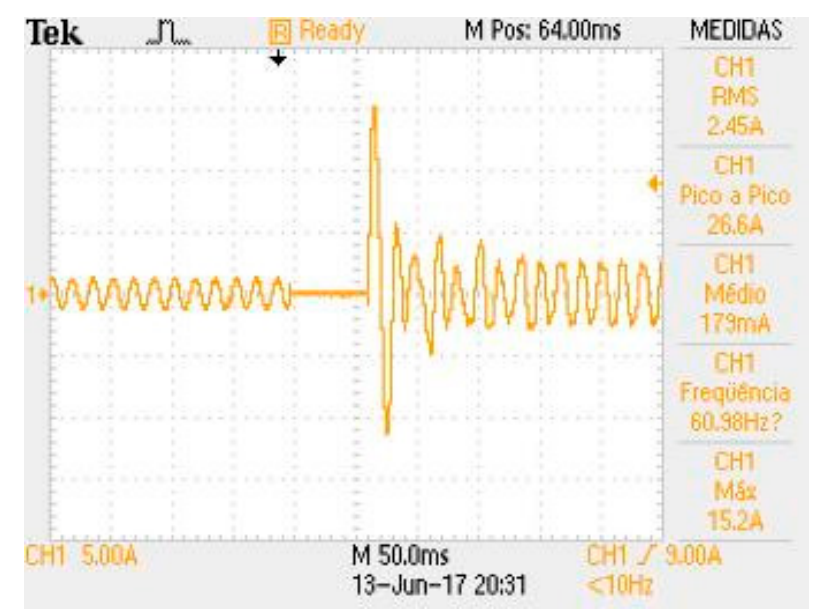

Figure 7. Typical current for the common form of delta connection $-\Delta t=50 \mathrm{~ms}$. (Vertical scale -5 A/division; Horizontal scale $-50 \mathrm{~ms}$ per division).

For the tests with the delta connection in the preferential form and common form, $\Delta t$ with a value of $50 \mathrm{~ms}$, the results of the values of the amplitude of the switching current are shown in Table 2.

From the results of Table 2 and a comparison with all the previous results, it is noted that the reduction of the value of $\Delta t$ causes a significant reduction in the amplitude of the switching current, regardless of the form of connection, as expected. On the other hand, the results confirm that, as also expected, for the same form of delta connection the reduction of $\Delta t$ tends to decrease the amplitude of the switching current.

In Figure 8 the waveform of the switching current, in the function of time, is shown in one of the ten starts.

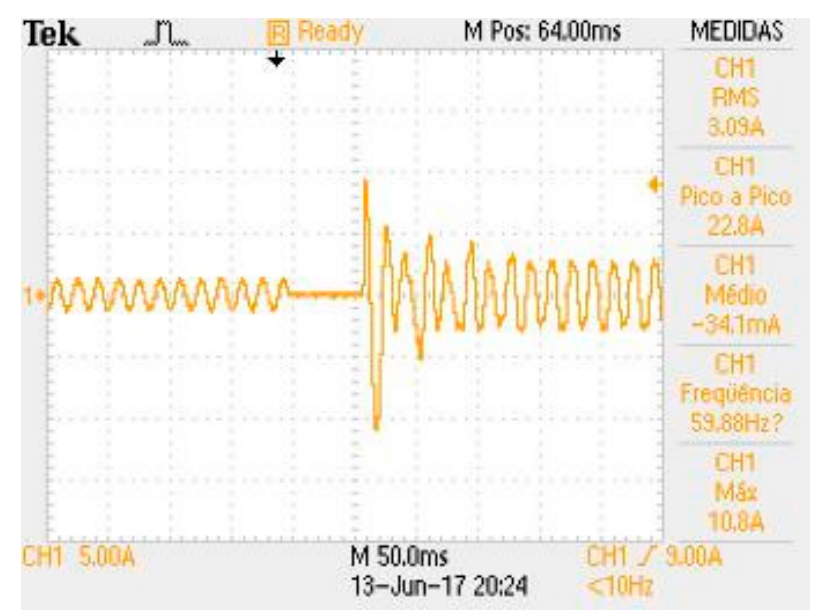

Figure 8. Typical current waveform for the preferential form of delta connection $-\Delta t=50 \mathrm{~ms}$ (Vertical scale $-5 \mathrm{~A}$ /division; Horizontal scale $-50 \mathrm{~ms}$ per division).

In this case, the current peak also has negative polarity.

\section{Conclusions}

The results presented in this work show that for the widely spread option of the star-delta start of induction motors, for which there are two possible forms of the delta connection of the stator winding, one has a switching current with a lower average value of amplitude and is, therefore, considered the preferential form. The other form, on average, has a greater value of the amplitude of the switching current and is, curiously, the most commonly indicated and recommended form. 
Thus, the choice between one of these forms has important consequences, since the amplitude of the switching current is one of the most recognized disadvantages of this starting option due to the need for careful analysis and setting of the relaying system for the motor's protection.

This situation becomes even more critical since the star-delta start shall remain for a long time as the very first choice for drive motor systems despite the undeniable growing competition offered by the other start options, based on power electronics components. Thus, the methodology of comparison of the options available for the star-delta start proposed and implemented here, based on an adequately developed arrangement of tests for an induction motor of common use, running idle, experimentally indicates that the influence of the connection effectively exists, which is significant and overlaps with the effect of the loss of speed during the switching time interval, along with the inertia of the motor shaft rules.

The results also confirm the influence of the residual magnetism of the magnetic circuit of the motor, which explains why the peak of the switching current may have a statistical nature, by including the negative polarity. The evaluation in different phases did not result in a variation in the results, so the results of the three-phase system were not presented, since the results are equivalent for each phase.

Lastly, it is important to reinforce that, although this analyzed issue is not so widely present in the literature, the obtained results favor the deepening in studies looking for economically feasible ways to mitigate this switching current, even for the case of the preferential form. This paper shows that there must be an evaluation of the preferred connection depending on the conditions in which the motor is used; using a standard form in all conditions can cause greater losses. For this reason, the evaluation of the motor connection type is a matter that must be checked in order to improve the efficiency of electric motors. Other time intervals can be evaluated to check their influence on the shape of the star-delta starting.

Author Contributions: Writing-original draft preparation, J.A.I.; conceptualization, formal analysis, S.H.L.C. and C.A.C.V.; methodology, S.F.S.; writing-review and editing, V.R.Q.L. and R.G.O.; writing-review and editing, A.N.; supervision, K.-C.Y. All authors have read and agreed to the published version of the manuscript.

Funding: This work was supported by Supported by project PLATAFORMA DE VEHÍCULOS DE TRANSPORTE DE MATERIALES Y SEGUIMIENTO AUTÓNOMO-TARGET. 463AC03, SA063G19. Project co-financed with Junta Castilla y León, Consejería de Educación and FEDER funds.

Institutional Review Board Statement: Not applicable.

Informed Consent Statement: Not applicable.

Acknowledgments: Al Proyeto: Uso de algoritmos y protocolos de comunicación en dispositivos con énfasis en la privacidad de los datos, and Laboratório de Telecomunicações de Portugal IT—Branch Universidade da Beira Interior, Covilhã.

Conflicts of Interest: The authors declare no conflict of interest.

\section{References}

1. Udovichenko, A.V. New Energy Saving Multizone Alternating-Voltage Soft Starters of Induction Machines. In Proceedings of the International Conference and Seminar on Micro/Nanotechnologies and Electron Devices Proceedings, Erlagol, Russia, 30 June-4 July 2011; pp. 415-419. [CrossRef]

2. Mallick, T.C.; Dhar, S.; Khan, J. Artificial Neural Network Based Soft-Starter for Induction Motor. In Proceedings of the 2nd International Conference on Electrical Information and Communication Technologies (EICT), Khulna, Bangladesh, 10-12 December 2015; pp. 228-233. [CrossRef]

3. Cistelecan, M.V.; Ferreira, F.J.T.E.; Popescu, M. Adjustable Flux Three-Phase AC Machines with Combined Multiple-Step Star-Delta Winding Connections. IEEE Trans. Energy Convers. 2010, 25, 348-355. [CrossRef]

4. Mircevski, S.A.; Andonov, Z. An Approach to Laboratory Training in Electric Drives. IFAC Proc. Vol. 1997, 30, 211-215. [CrossRef]

5. Rathore, T.S. A Systematic Method for Finding the Input Impedance of Two-terminal Networks. IETE J. Educ. 2017, 58, 83-89. [CrossRef] 
6. Yan, B.; Wang, X.; Yang, Y. Starting Performance Improvement of Line-Start Permanent-Magnet Synchronous Motor Using Composite Solid Rotor. IEEE Trans. Magn. 2018, 54, 1-4. [CrossRef]

7. Rabbi, S.F.; Zhou, P.; Rahman, M.A. Design and Performance Analysis of a Self-Start Radial Flux-Hysteresis Interior Permanent Magnet Motor. IEEE Trans. Magn. 2017, 53, 1-4. [CrossRef]

8. Hu, Y.; Chen, B.; Xiao, Y.; Shi, J.; Li, L. Study on the Influence of Design and Optimization of Rotor Bars on Parameters of a Line-Start Synchronous Reluctance Motor. IEEE Trans. Ind. Appl. 2020, 56, 1368-1376. [CrossRef]

9. Yan, B.; Wang, X.; Yang, Y. Comparative Parameters Investigation of Composite Solid Rotor Applied to Line-Start PermanentMagnet Synchronous Motors. IEEE Trans. Magn. 2018, 54, 1-5. [CrossRef]

10. Albert, E.; Clayton, D. A Mathematical Development of the Theory of the Magnetomotive Force of Windings. J. Inst. Electr. Eng. 1923, 61, 749-787.

11. Ferreira, F.J.T.E. On the Star, Delta and Star-Delta Stator Winding Connections Tolerance to Voltage Unbalance. In Proceedings of the IEEE International Electric Machines \& Drives Conference (IEMDC), Coeur d'Alene, ID, USA, 10-13 May 2015; pp. 1888-1894. [CrossRef]

12. Goh, H.H.; Looi, M.S.; Kok, B.C. Comparison between Direct-On-Line, Star-Delta and Auto-Transformer Induction Motor Starting Method in Terms of Power Quality. In Proceedings of the International Multiconference of Engineers and Computer Scientists (IMECS), Hong Kong, China, 18-20 March 2009; pp. 1-6.

13. Misir, O.; Raziee, S.M.; Hammouche, N.; Klaus, C.; Kluge, R.; Ponick, B. Prediction of Losses and Efficiency for Three-Phase Induction Machines Equipped with Combined Star-Delta Windings. IEEE Trans. Ind. Appl. 2017, 53, 3553-3587. [CrossRef]

14. Abdel-Hamid, M.N. Improved Starting Process Alternative to Conventional Star-Delta Switching of A-C Meters. IEEE Trans. Appl. Ind. 1963, 82, 52-60. [CrossRef]

15. Vansompel, H.; Sergeant, P.; Dupre, L.; Bossche, A. A Combined Wye-Delta Connection to Increase the Performance of Axial-Flux PM Machines with Concentrated Windings. IEEE Trans. Energy Convers. 2012, 27, 403-410. [CrossRef]

16. Vercelli, L. Rechts-und Linkslauf der Motoren bei Y-D-Anlauf. Elektron. Ch 1978, 53, 1-10.

17. Konuhova, M.; Ketners, K.; Ketnere, E.; Klujevska, S. Research of the Effect of the Rotor Constant upon the Attenuation Characteristic if the Induction Motor Residual Voltage under the Switching Regime. In Proceedings of the Problems of PresentDay Electrotechnics-2010 (PPE-2010): Conference Proceedings, Kiev, Ukraine, 1-3 June 2010; National Academy of Sciences of Ukraine: Kiev, Ukraine, 2010; pp. 152-155.

18. Ferreira, F.J.T.E.; Ge, B.; Quispe, E.C.; de Almeida, A.T. Star-and Delta-Connected Windings Tolerance to Voltage Unbalance in Induction Motors. In Proceedings of the International Conference on Electrical Machines (ICEM), Berlin, Germany, 2-5 September 2014; pp. 2045-2054. [CrossRef]

19. Siemens, A.G. Grundlagen der Niederspannungs-Schalttechnik, Seite 21 B-1 Zum 21 B-4. 2008. Available online: https:/ / cache. industry.siemens.com/dl/files/099/34973099/att70195/v1/Grundlagen_der_Niederspannungs_Schalttechnik.pdf (accessed on 6 December 2020).

20. Bradley, A.; Low-Voltage Switchgear and Controlgear. Technical Document. 3-10, Rockwell Automation. 2009. Available online: http:/ / literature.rockwellautomation.com/idc/groups/literature/documents/rm/lvsam-rm001-en-p.pdf (accessed on 6 December 2020).

21. Moros, O.; Gerling, D. Geometrical and Electrical Optimization of Stator Slots in Electrical Machines with Combined Wye-Delta Winding. In Proceedings of the 2014 International Conference on Electrical Machines (ICEM), Berlin, Germany, 2-5 September 2014; pp. 2026-2030. [CrossRef]

22. Stefenon, S.F.; Seman, L.O.; Schutel Furtado Neto, C.; Nied, A.; Seganfredo, D.M.; da Luz, F.G.; Sabino, P.H.; Torreblanca González, J.; Quietinho Leithardt, V.R. Electric Field Evaluation Using the Finite Element Method and Proxy Models for the Design of Stator Slots in a Permanent Magnet Synchronous Motor. Electronics 2020, 9, 1975. [CrossRef]

23. Kasburg, C.; Stefenon, S.F. Deep Learning for Photovoltaic Generation Forecast in Active Solar Trackers. IEEE Lat. Am. Trans. 2019, 17, 2013-2019. [CrossRef]

24. Stefenon, S.F.; Kasburg, C.; Nied, A.; Klaar, A.C.R.; Ferreira, F.C.S.; Branco, N.W. Hybrid Deep Learning for Power Generation Forecasting in Active Solar Trackers. IET Gener. Transm. Distrib. 2020, 14, 5667-5674. [CrossRef]

25. Ninno Muniz, R.; Stefenon, S.F.; Gouvêa Buratto, W.; Nied, A.; Meyer, L.H.; Finardi, E.C.; Marino Kühl, R.; de Sá, J.A.S.; da Rocha, B.R.P. Tools for Measuring Energy Sustainability: A Comparative Review. Energies 2020, 13, 2366. [CrossRef]

26. Stefenon, F.S.; Ademir, N. FEM Applied to Evaluation of the Influence of Electric Field on Design of the Stator Slots in PMSM. IEEE Lat. Am. Trans. 2019, 17, 590-596. [CrossRef]

27. Orosz, T.; Rassõlkin, A.; Kallaste, A.; Arsénio, P.; Pánek, D.; Kaska, J.; Karban, P. Robust Design Optimization and Emerging Technologies for Electrical Machines: Challenges and Open Problems. Appl. Sci. 2020, 10, 6653. [CrossRef]

28. Orosz, T. Evolution and Modern Approaches of the Power Transformer Cost Optimization Methods. Period. Polytech. Electr. Eng. Comput. Sci. 2019, 63, 37-50. [CrossRef]

29. Orosz, T.; Sleisz, Á.; Tamus, Z.Á. Metaheuristic Optimization Preliminary Design Process of Core-Form Autotransformers. IEEE Trans. Magn. 2016, 52, 1-10. [CrossRef]

30. Pánek, D.; Orosz, T.; Karban, P. Artap: Robust Design Optimization Framework for Engineering Applications. arXiv 2019, arXiv:1912.11550. 
31. Stefenon, S.F.; Kasburg, C.; Freire, R.Z.; Silva Ferreira, F.C.; Bertol, D.W.; Nied, A. Photovoltaic Power Forecasting Using Wavelet Neuro-Fuzzy for Active Solar Trackers. J. Intell. Fuzzy Syst. 2021, 40, 1083-1096. [CrossRef]

32. Rolim, C.O.; Schubert, F.; Rossetto, A.G.; Leithardt, V.R.; Geyer, C.F.; Westphall, C. Comparison of a Multi Output Adaptative Neuro-Fuzzy Inference System (MANFIS) and Multi Layer Perceptron (MLP) in Cloud Computing Provisioning. In Proceedings of the 29th Brazilian Symposium on Computer Networks and Distributed Systems, Campo Grande, Brazil, 30 May-3 June 2011

33. Ferreira, F.J.T.E.; de Almeida, A.T. Novel Multiflux Level, Three-Phase, Squirrel-Cage Induction Motor for Efficiency and Power Factor Maximization. IEEE Trans. Energy Convers. 2008, 23, 23-109. [CrossRef]

34. Furqani, J.; Kawa, M.; Kiyota, K.; Chiba, A. Current Waveform for Noise Reduction of a Switched Reluctance Motor Under Magnetically Saturated Condition. IEEE Trans. Ind. Appl. 2018, 54, 213-222. [CrossRef]

35. Misir, O.; Ponick, B. Analysis of Three-Phase Induction Machines with Combined Star-Delta Windings. In Proceedings of the 2014 IEEE 23rd International Symposium on Industrial Electronics (ISIE), Istanbul, Turkey, 1-4 June 2014; pp. 756-761. [CrossRef]

36. Misir, O.; Raziee, S.M.; Hammouche, N.; Klaus, C.; Kluge, R.; Ponick, B. Calculation Method of Three-Phase Induction Machines Equipped with Combined Star-Delta Windings. In Proceedings of the 2016 XXII International Conference on Electrical Machines (ICEM), Lausanne, Switzerland, 4-7 September 2016; pp. 166-172. [CrossRef]

37. Sang-Hoon, K. Modeling of Alternating Current Motors and Reference Frame Theory. In Electric Motor Control; Elsevier: Amsterdam, The Netherlands, 2017. [CrossRef]

38. Cabral, S.H.L.; Matos, J. Simplified Modelling of Hysteresis for Power System Transformers Studies. In International Conference on Power Systems Transients: Conference Proceedings; IPST 2001 (Federal University of Rio de Janeiro): Rio de Janeiro, Brazil, 2001; pp. 61-64. 